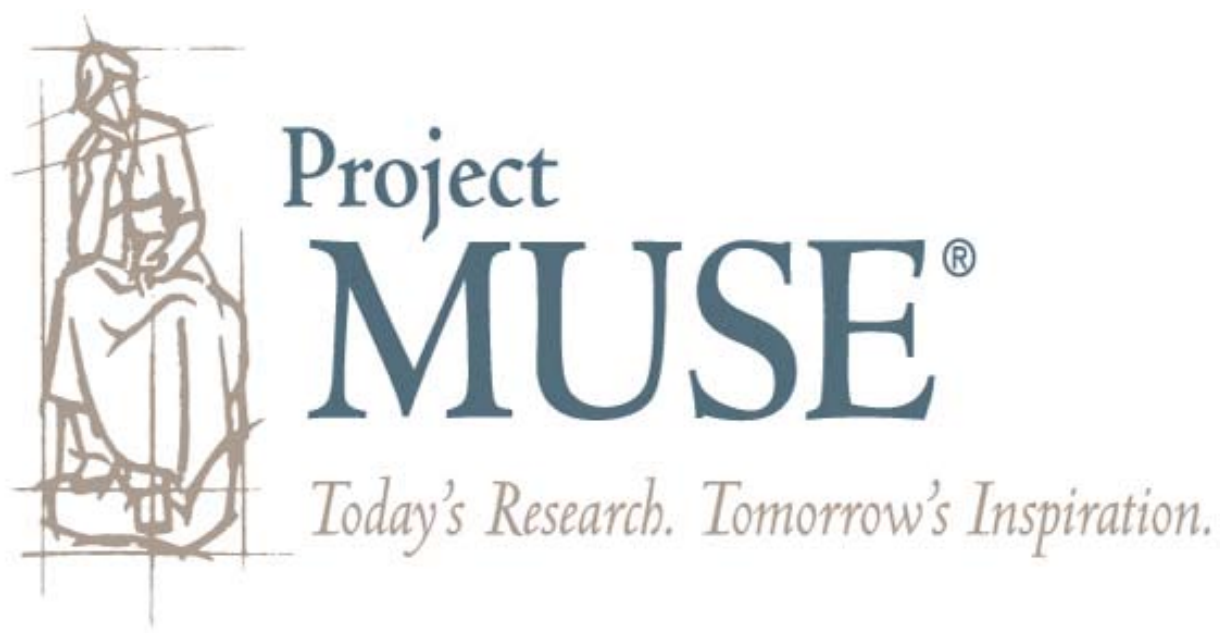




\title{
Ideologically Illogical? Why Do the Lower-Educated Dutch Display so Little Value Coherence?
}

\author{
Peter Achterberg, Erasmus University Rotterdam, The Netherlands \\ Dick Houtman, Erasmus University Rotterdam, The Netherlands
}

In studies of mass ideology, it is often found that political values are ordered two-dimensionally among the public at large. In a first economic dimension, equality is contested; in a second cultural one, individual freedom is contested. While this general rule of two-dimensionality applies to the public at large, there are large differences between educational categories. While two-dimensionality is found for the lower educated, the higher educated order their values along a single dimension and hence show more value coherence. Using a recent Dutch national survey, we show that these differences between the higher and the lower educated cannot be explained by differences in political competence. Instead, a combination of cultural and economic insecurity is responsible for the lower levels of value coherence among the lower educated.

In trying to find validation for the ideological dyad between "left" and "right," or in his words "liberals" and "conservatives," Kerr found in 1952 that, much like personal excellence, political values do not always go together in a logical and coherent fashion. "[I]n short, the liberal and the conservative, like the genius probably is an hypothetical individual who does not exist, unless the term is made specific to sub-continua instead of to an absolute general continuum." (Kerr 1952, italics in original) Since then, there have been numerous studies about the way political values and opinions on policy measures are organized among the public at large. What sociologists and political scientists alternatively refer to as value coherence (Gibbins and Nevitte 1985), dimensionality (Fleishman 1988), consistency (Moskowitz and Jenkins 2004), constraint (Bartle 2000), or congruence (Van Snippenburg, Hageman and Hendriks Vettehen 2002) boils down to the organization of political values - the degree to which leftist or progressive values on one issue coherently go together with leftist or progressive ones on others, and to which rightist or conservative

We are grateful to Roy Kemmers for his invaluable research assistance. Also, we would like to thank Jolien "Suzy Lee" Veensma for her comments on earlier versions of this article. Direct correspondence to Peter Achterberg, Department of Sociology, Faculty of Social Sciences, Erasmus University Rotterdam, P.O. Box 1738, 3000 DR, Rotterdam, The Netherlands. E-mail: p.achterberg@fsw.eur.nl. 
values on one issue coherently go together with rightist or conservative values on others.

However the phenomenon is conceptualized, many sociologists and political scientists have tried to find out how political values are organized into one, two or even more dimensions - with notable resilient results. Since Lipset (1959) proposed that the working class is as progressive towards issues of economic distribution (egalitarian) as it is conservative when it comes to non-economic issues (authoritarian), numerous studies have demonstrated that there are in fact two separate ideological domains (compare Converse 1964; Evans, Heath and Lalljee 1996; Feldman 2003; Felling and Peters 1986; Fleishman 1988; Heath, Evans and Martin 1994; Kelly and Chambliss 1966; Middendorp 1991; Mitchell 1966; O'Kane 1970; Scheepers, Eisenga and Van Snippenburg 1992). Middendorp (1991:76) rightly summarizes his own - and all other - findings on the subject as follows: "...the two values underlying most model elements ....are those of freedom and equality: the former applied to the political socio-cultural domain; the latter applied to the socio-economic domain." Moreover, these two dimensions - an economic dimension of egalitarianism vs. laissez-faire and a cultural one of authoritarianism vs. libertarianism are, according to these studies, totally unrelated to each other. Whether people favor economic equality and welfare state intervention has, generally speaking, nothing to do with their values on individual freedom or their opinions on a radical restoration of social order. According to this strand of research, egalitarian values are just as likely (or unlikely) to be combined with authoritarian values as with libertarian ones. In other words, knowing someone's values on economic matters does not lead to a correct prediction of what one will think about cultural matters. There is no or very little coherence between the two value dimensions.

Yet, research clearly demonstrates that there are important differences in value coherence between social strata. Studies by Jennings (1992) and Middendorp (1991) have shown that compared to the masses, there is more value coherence among political elites. Studies among religious specialists (Olson and Carrol 1994), cultural elites (Lerner, Nagai and Rothman 1991), lawyers (Herzon 1980) and intellectual elites (Ladd and Lipset 1975; Lipset 1982) all come to the same conclusion: more value coherence exists among elites. In the case of these elite groups, egalitarian values on the economic domain coherently go together with libertarian ones on the cultural domain, while laissez-faire values on the former "logically" go together with authoritarian ones on the latter. Among elites, political values are more consistently ordered into a single dimension of progressiveness vs. conservatism. A recent study by Houtman, Achterberg and Derks (2008) has shown that ideological coherence is much stronger among the higher educated than among the lower educated, whose 
ideological beliefs are ordered more incoherently in a two-dimensional fashion (see also Carmines and Stimson 1982).

Many studies on the subject, however, are limited to the question of how political values are organized among the public at large and among elites, without providing a clear answer to the question of why these values are organized less coherently among the former than among the latter. Therefore, in this article we not only compare the dimensionality of political values among the public at large with that among various educational categories, but we also study how differences between these categories can be explained.

\section{Two Explanations for Value Coherence}

In his classic work on ideology, Converse (1964) offers some useful points of departure. He objects to the assumption that the public at large (the mass), like society's upper layer (the elite), integrates political values into a single ideological dimension that ranges from conservative to progressive. Such ideological one-dimensionality or value coherence - Converse uses ideological constraint - is only characteristic of the elite. According to Converse (1964:215), the assumption that these "constraints visible at the elite level are mirrored in the mass public..." is untenable, because the public at large combines conservative values about certain issues with progressive ones about others. Hence, for the lower educated an image of ideological fragmentation emerges, while the higher educated feature high levels of ideological coherence: "(I)deologically constrained belief systems are... more common in upper than in lower social strata." (Converse 1964:248)

All aforementioned studies partially concur, but also partially contradict, Converse's argument. On the one hand, it is clear that ideological constraint is in fact higher than expected among the public at large. Although there is no such thing as just one political dimension of conservatism vs. progressiveness, the bi-dimensional structure repeatedly found in ideological values illustrates that Converse's (1964:216) statement that "the (masses) lack the contextual grasp of the system to recognize how they should respond to (an issue) without being told by elites who hold their confidence" is somewhat exaggerated. On the other hand, though, it is clear that Converse is right when he argues that there is an important difference between the masses and the elite in ideological coherence. Whereas egalitarian values go hand in hand with libertarian ones among higher educated elites, such coherence cannot be found among the lower educated masses. That is why we will test our first hypothesis: while for the public at large there is no coherence between egalitarian and authoritarian values, the degree to which these values are organized 
coherently increases with educational level. In order to explain these differences in (in)coherence between the higher and lower educated, we put forward two explanations.

\section{Political Competence and Ideological Beliefs}

The first theory, which has been popular since the 1960s, focuses on political competence for explaining differences in ideological coherence. Converse (1964:211) explains the contrast in coherence between the masses and the elite by a functionalist theory on political systems, in which political ideology is formed at the top by well-informed elites: "(The) shaping of any range of belief systems into apparently logical wholes that are credible to large numbers of people is an act of creative synthesis characteristic of only a miniscule proportion of any population." These ideological beliefs are then passed down in the form of "packages." In daily practice, this process of diffusion is curdled though. This curdling of ideological diffusion may be caused not only by the fact that all sorts of interests can interfere with the diffusion, but also that "(C)onstraint through diffusion... implies a dependence upon the transmission of information. If information is not successfully transmitted, there will be little constraint..." (Converse 1964:212) Practically, though, it appears that "Very little information 'trickles down' very far." A successful transmission of complex political information depends on whether one is equipped with a "cognitive structure that subsumes content of wide scope and diversity [which is] capped by concepts of a high order of abstraction" (Campbell et al. 1960:193), which allows one "to make sense of a broad range of events." In a study of "don't know" answers, Bourdieu (1984) showed that the degree to which people can answer political questions in a questionnaire depends on level of education, illustrating that the higher educated make sense of a broader range of questions and have the ability to answer those questions. One's cognitive ability (Carmines and Stimson 1982), political capital (Bourdieu 1984), or political competence (Jackson and Marcus 1975) is thus said to ensure a coherent ideological worldview.

Many empirical studies take for granted a positive relationship between educational level and political competence. Some researchers even seem to think that they can measure political competence by using a measure for education (Price 1999) or mix it up with education (Carmines and Stimson 1982) - which, of course is a bridge too far, as Van Snippenburg, Hageman and Hendriks Vettehen (2002) rightfully notice.The argument that the political knowledge and competence of the higher educated is responsible for their higher levels of ideological coherence is widely accepted, too (e.g., Fiske and Kinder 1981; Judd and Krosnick 1989; Lerner, Nagai and Rothman 1991; Zaller 1992). Forty years after its first conception, the idea 
is still held that political competence plays an important role in shaping the structure of ideological beliefs. According to this theory, ideological coherence depends on political competence, while political competence itself depends on educational level (Bartle 2000; Converse 1964). Thus, our second hypothesis is that value incoherence among the lower educated is caused by their low level of political competence.

\section{Social Position, Economic and Cultural Insecurity}

Although political competence is central to Converse's theory, he suggests that interests are also likely to affect ideological (in)coherence. The exact nature of these interests, and how exactly these affect ideological (in) coherence has, however, remained largely unexplored. Recent work on the relationship between social position, interests and political values may shed some light on these questions (e.g., Achterberg 2006; Houtman 2003; Houtman, Achterberg and Derks 2008). The central argument is that for a sound understanding of the origins of egalitarianism and authoritarianism it is necessary to supplement these two types of values with a distinction between two types of social position: one's economic (class) position and one's cultural position - or one's economic and one's cultural capital (compare Bourdieu 1986).

Once this distinction between economic and cultural position is adopted, empirical evidence shows that egalitarianism can be attributed to the strength of one's economic position. If a person is in a weak position (which means: low level of education, low income, high risk of unemployment) and suffers from economic insecurity, he or she is more inclined to be pro-welfare state, pro-state intervention in the economy, pro-financial redistribution and have egalitarian values (De Witte 1997; Marshall et al. 1988; Svallfors 1991; Wright 1985). A preference for laissez-faire values can then be attributed to a strong economic position. This, of course, is not remarkable at all, as it is completely in line with what class analysts have argued since the $19^{\text {th }}$ century and is one of the mainstays of political sociology: that values held about equitable distribution are a direct reflection of class interests (Lipset 1981). Also, of course, the fact that the working class has traditionally been the channel for socialism, illustrates the correctness of this theoretical idea (see Alford 1967; Nieuwbeerta 1995).

Yet, unlike egalitarianism, authoritarianism is not caused by one's economic position. In this case, it is not economic interests that are decisive, but one's cultural interests related to the amount of cultural capital one possesses. As cultural capital increases, people decreasingly hold conservative or authoritarian values on cultural matters pertaining to individual freedom and cultural diversity: those with little cultural capital reject libertarian values and hold conservative ones (Achterberg and 
Houtman 2006; Lamont 1987). Whereas the antecedents of economic progressiveness lie in trying to reduce economic insecurity, the antecedents of cultural conservatism lie in trying to reduce cultural insecurity. Empirical studies show that an emphasis on order and on strong authority is grounded in feelings of discontent (anomia) (see for example, Blank 2003; Eisenga and Scheepers 1989; Lutterman and Middleton 1970; McDill 1961; Roberts and Rokeach 1956; Srole 1956) and that this is prevalent among those with little cultural capital (the lower educated) and not among those with ample cultural capital (the higher educated) (e.g., Dekker and Ester 1987; Grabb 1979; Grabb 1980; Houtman 2001, 2003, 2004).

The ideological profile of the lower educated, in short, is indeed incoherent, as Lipset (1959) argued a long time ago: because of their economically insecure position they are egalitarian and because of their culturally insecure position they are authoritarian at the same time. Although the higher educated prefer laissez-faire economic values and libertarian cultural ones, an important, but rarely noted, observation is that differences between the higher and lower educated in authoritarianism are greater than in egalitarianism (see Houtman 2003). The fact that the higher educated hold stronger libertarian views pertaining to cultural issues, but barely hold laissez-faire values pertaining to economic matters, suggests that economic interests only lead to egalitarianism when people are in an economically insecure position. We thus expect that the economic insecurity of the lower educated leads to egalitarian values, but that the economic security of the higher educated does not lead to laissez-faire values. Following this logic, the consequences of economic (in)security for economic values differ for the higher and lower educated, whereas the consequences of cultural insecurity for cultural values are basically similar. Their culturally insecure position leads the lower educated to authoritarian values, and their economically insecure position leads them to egalitarianism. Hence, for the lower educated an incoherent ideological profile emerges. As their culturally secure position leads the higher educated to libertarian values and their economically secure position does not lead them to laissez-faire values, a coherent ideological profile is more likely for this category. The crucial third hypothesis that may be derived from this theory is: ideological incoherence can mainly be found among the lower educated because they are in an economically and culturally insecure position.

\section{Data and Measurement}

In order to test the hypotheses, we used data that were collected in 2006 in the Netherlands. The data collection was done using Centerdata's panel (University of Tilburg), which is representative of the Netherlands. A total of 2,682 individuals were selected to participate in the study, of which 1,972 
respondents completed the questionnaire, giving a response rate of 73 percent. A comparison with official statistics from Statistics Netherlands (Centraal Bureau voor de Statistiek) showed that older people, higher income groups and higher educational groups were overrepresented in the sample, which we corrected using a weighting factor. ${ }^{1}$

To measure authoritarianism we used a seven-item selection from the F-scale for authoritarianism by Adorno et al. (1950). We asked the respondents to indicate whether they agreed (1 totally agree, 2 agree, 3 neither agree nor disagree, 4 disagree, 5 totally disagree, 6 don't know) with the following statements:

1. Young people often revolt against social situations that they find unjust: however, when they get older they ought to become resigned to reality.

2. What we need are fewer laws and institutions and more courageous, tireless and devoted leaders whom people can trust.

3. Because of rapid changes it is hard to distinguish good from bad.

4. There are two sorts of people: the strong and the weak.

5. Most of our social problems would be solved if we could somehow get rid of the immoral, crooked and feebleminded people.

6. If people would talk less and work harder, everything would be better.

7. Because of the many opinions on good and bad, it is not clear what is what.

In order to test the first hypothesis, these seven items were used. The "don't know" answers were coded as missing.

To measure egalitarianism we used five items that were previously used by Houtman (2003). Respondents were asked to what degree they agreed ( 1 totally agree, 2 agree, 3 neither agree nor disagree, 4 disagree, 5 totally disagree, 6 don't know) with the following statements:

1. The state should make social benefits higher.

2. There is no longer any real poverty in the Netherlands.

3. Large income differences are unfair because in essence everyone is equal.

4. The state should intervene to reduce income differences.

5. Companies should be obliged to allow their employees to share in the profits. 
In order to test the first hypothesis, these five items were used. The "don't know" answers were coded as missing.

Value coherence was measured as in Achterberg (2006) by constructing a scale for egalitarianism from the five items above, in which higher scores stand for progressive values, and then by standardizing the scale (Cronbach's $\alpha=.78$ ). Also, using the items for authoritarianism, a scale for libertarianism was made by recoding the items so that higher scores stand for more progressive values and then by adding them together (Cronbach's $\alpha=.74)$. This scale was standardized, too. Finally these two scales, in which negative scores stand for conservative values and positive ones for progressive ones, were multiplied. As a result, people scoring either positively (coherently progressive) or negatively (coherently conservative) on both scales obtain high positive scores on the new scale for coherence. Those who combine progressive values on one scale with conservative ones on the other, feature a combination of positive and negative scores that result in negative scores on the scale for coherence. ${ }^{2}$ Although it is constructed using the items for egalitarianism and authoritarianism, the resulting measure for political coherence does not correlate strongly with either scale (.001 and $-.08 ; \mathrm{p}<.01$ respectively).

To measure political competence, following Bourdieu (1984), we used all 12 items for egalitarianism and authoritarianism. We recoded these items in such a way that respondents got a score of 1 if they gave a valid response and a score of 0 if they did not know). In order to check whether the 12 resulting dummy variables could be combined into a new variable measuring political competence, a factor analysis was done. This showed that all items loaded strongly on the first factor which had an eigenvalue of 7.37 and that explained 61 percent of the variance within all items. A new scale was constructed by taking the items together, yielding a scale running from 0 , for those who did not have an answer to any of the 12 questions, to 12 , for those who had responded validly to all 12 items (Cronbach's $\alpha=.94$ ). Although it is once again constructed using the items for authoritarianism and egalitarianism, the resulting scale for political competence does not correlate with either of these two scales (.000 and .001 respectively).

Educational level was measured using the highest level attained. Respondents have been recoded into four educational categories: Iow (only primary education), medium low (VMBO), medium high (HAVO/ VWO/MBO) and high (College/Academic). In Table 1, we estimate the relationships between educational level and the two ideological scales by means of regression analysis. This shows that the educational categories do indeed differ more strongly with respect to authoritarianism than with respect to egalitarianism. ${ }^{3}$

Economic insecurity was measured using three items. Firstly, we asked the respondents whether or not it was hard to manage their household 
Table 1: Education, Authoritarianism and Egalitarianism

\begin{tabular}{lcc}
\hline Independents & Authoritarianism & Egalitarianism \\
\hline Low education (= reference) & - & - \\
Medium-low education & $-.06 \mathrm{n} . \mathrm{s}$. & $-.09^{*}$ \\
Medium-high education & $-.25^{\star * *}$ & $-.20^{\star * *}$ \\
High education & $-.40^{* * *}$ & $-.31^{* *}$ \\
\hline $\mathrm{R}^{2}$ & .10 & .04 \\
\hline
\end{tabular}

Note: Entries are $\beta \mathrm{s}(\mathrm{N}=1,989)$

${ }^{*} \mathrm{p}<.01 \quad{ }^{* * *} \mathrm{p}<.001 \quad$ n.s. not significant

on the household income ( 1 very hard, 2 hard, 3 rather hard, 4 rather easy, 5 easy, 6 very easy). This item was recoded in such a way that higher scores stand for more economic insecurity. Secondly, we asked whether a respondent was unemployed at the moment of the interview (1 not unemployed, 2 partially unemployed, 3 totally unemployed). Thirdly, we asked the respondents into which of four categories their monthly net household income fell: 1) 2,601 or more 2) 1,801 to 2,600 3) 1,151 to 1,800 and 4) 1,150 Euros or less. Factor analysis on these three items yielded a first factor (with an eigenvalue of 1.57) explaining about 52 percent of the variance. The reliability of this scale (Cronbach's $\alpha=.55)$ was rather modest, but given its face validity and the limited number of items, we constructed the scale by standardizing the items and then adding them up. Higher scores indicate higher levels of economic insecurity.

Cultural insecurity was measured using a slightly altered version of Srole's widely used scale of anomia (Srole 1956). ${ }^{4}$ We asked the respondents whether they agreed ( 1 totally agree, 2 agree, 3 neither agree nor disagree, 4 disagree, 5 totally disagree, 6 don't know) with the following statements:

1. These days a person doesn't really know whom he can count on.

2. Nowadays a person has to live pretty much for today and let tomorrow take care of itself.

3. In spite of what some people say, the lot of the average man is getting worse, not better.

4. It's hardly fair to bring children into the world, the way things look for the future.

A factor analysis of the responses to these four items showed that there was a first factor with an eigenvalue of 2.17 explaining 54 percent of the variance. After standardizing and summing the items, we have constructed a scale for cultural insecurity. Higher scores stand for greater cultural insecurity (Cronbach's $\alpha=.71$ ). 
Figure 1. The One-dimensional Model

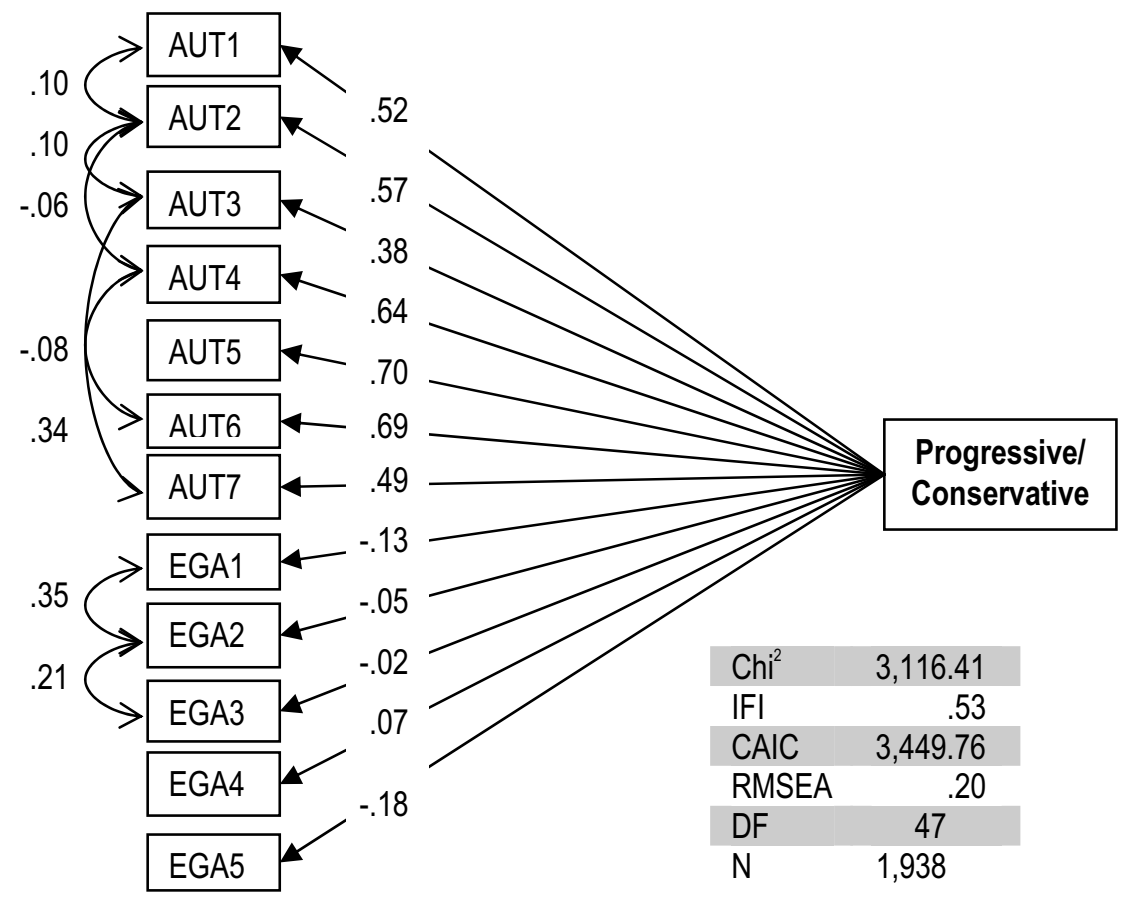

\section{Results}

\section{Two Independent Value Dimensions?}

Just as in other studies, the first step in our analysis is to find out whether there are in fact one or two value dimensions. Like Fleishman (1988) did earlier, we used the program LISREL (Jöreskog and Sörbom 1999) to perform a confirmatory factor analysis on the correlation matrix of the items for authoritarianism and egalitarianism in order to test whether there are two dimensions (see figures 1 and 2). ${ }^{5}$

Comparing the two models, which are identical except for the fact that an extra dimension has been added in the second model, it appears that the second model fits the data better than the first. The differences between the values for the chi-square and the $\mathrm{CAIC}^{6}$ for both models are quite large and, more importantly, statistically significant with just one degree of freedom difference between both models. Also, the values of $\mathrm{IFI}^{7}$ (which should be as close as possible to 1) and RMSEA ${ }^{8}$ (which should be close to 0 ) indicate a better fit for the second model.

The correlation between both value dimensions in Figure 2 is .02 and, more importantly, is not statistically significant. We can now safely draw the conclusion that there are two independent value dimensions 
Figure 2. The Two-dimensional Model

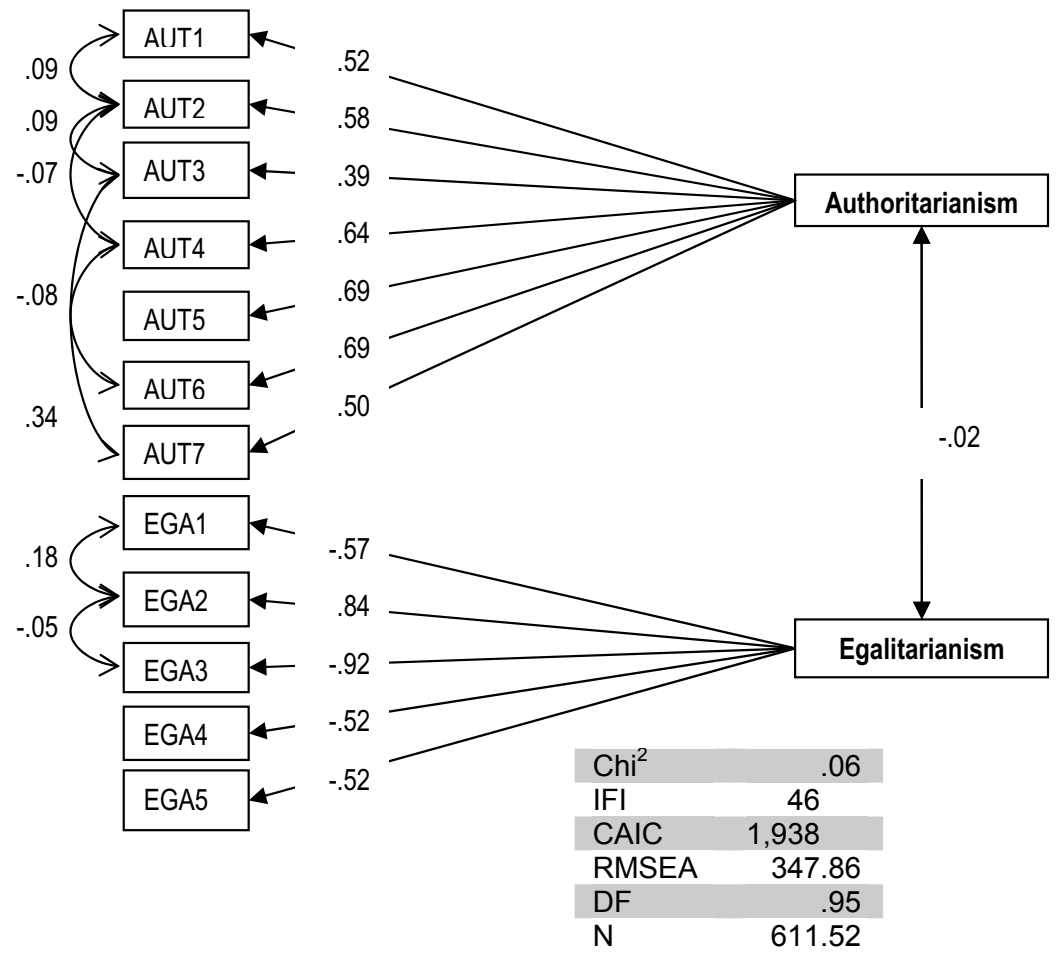

among the public at large: one cultural and the other economic. Whether one is progressive on one dimension has nothing to do with how one positions oneself on the other. In other words: being authoritarian does not necessarily lead to any laissez-faire values whatsoever. Knowing someone's cultural values, there is no way of predicting what he or she will think about economic redistribution and vice versa.

\section{Educational Level and Value Coherence}

Up to this point, like all other studies into the organization of ideological values, we have found that there are two independent value dimensions in the population as a whole. The next question that needs to be answered is whether this bi-dimensionality applies to all educational categories. In order to do this we first calculated a correlation matrix for each educational category separately. Then, we fitted the model presented in Figure 2 to the four resulting correlation matrices, assuming there are no differences in bi-dimensionality between the four categories. If there is a significant difference between the educational categories, the first model, which assumes there are no differences, should fit badly. Theoretically, though, the model should fit better if we do not assume that the correlation 
between authoritarianism and egalitarianism is equal for all educational categories. As the first hypothesis posits that ideological coherence rises with educational level, we should find a strong and negative correlation between the two ideological values for those with the highest educational level. Table 2 displays the fit statistics for a model that assumes equal factor structures for all educational levels (Model 1) and for three models that assume unequal ones (models 2, 3 and 4). In Model 2, we recalculated the correlation between authoritarianism and egalitarianism for the higher educated ${ }^{9}$ while the factor structures for the lowest educational levels are

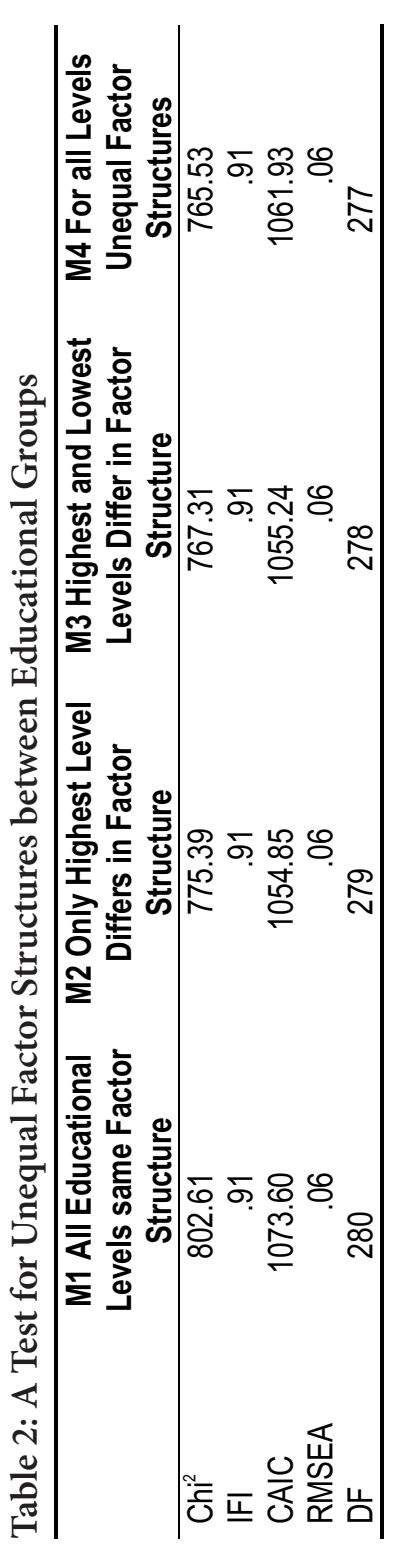

assumed equal. Comparing the fit statistics of this model to those of model 1 it is clear that the former fits better: while the values of IFI and RMSEA remain stable, the values of chi-square and CAIC decline significantly. For the same reasons, the Model 3 fits the data better than Model 2. In Model 3, correlations for the lowest and highest educational levels are recalculated, while these are assumed to be equal for the middle-level educational categories.

Finally, Model 4, which estimates a new factor structure for each educational category, does not fit the data better than Model 3: while the values for the IFI and RMSEA still remain stable, the chi-square and CAIC no longer improve significantly. The more parsimonious Model 3 is thus preferred. This means that there are no statistically significant differences in the relationship between authoritarianism and egalitarianism in the two middle educational categories: for these, the factor structures are equal. Figure 3 shows the differences in the correlation between egalitarianism and authoritarianism according to the third model.

For people with medium-low or medium-high levels of education, as for the population as a whole, there is virtually no relationship between authoritarianism and egalitarianism. However, for people with higher educational levels the relationship between the two ideological values is strong and significant. They tend to combine egalitarian with libertarian values or authoritarian with laissez-faire ones, displaying higher levels of value coherence. The reverse applies to the 
Figure 3. Differences between Educational Levels in the Correlation between Egalitarianism and Authoritarianism

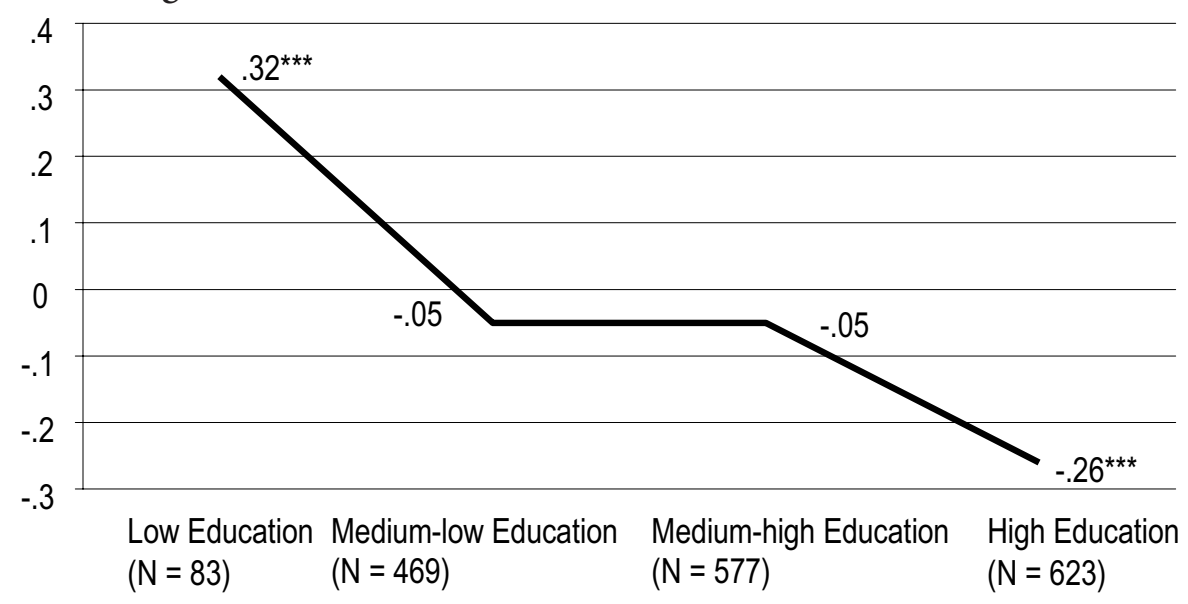

Note: ${ }^{* *} \mathrm{p}<.001$

lower educated. As they tend to combine egalitarian with authoritarian values or laissez-faire with libertarian ones, they display low levels of value coherence. The first hypothesis is therefore accepted. While for the public at large there is no coherence between egalitarian and authoritarian values, it increases with educational level. The next section explores how these differences in value coherence can be explained.

\section{Value Coherence, Political Competence and Insecurity}

We found, above, that the lower educated display less value coherence than the higher educated - which can be represented by a correlation between our measure for value coherence and educational level. ${ }^{10}$ This correlation of .09 is not particularly strong, but it is statistically significant $(p<.001$ : $\mathrm{N}=1,906)$. Next, we estimated a path model in which this relationship is decomposed into several paths. One path runs through political competence and other paths run through economic and cultural insecurity respectively (see Figure 4). Two conclusions may be drawn. First, although the higher educated do have more political competence, this does not lead them to order their values in a more coherent fashion. The second hypothesis, stating that the political competence of the higher educated is responsible for their higher levels of value coherence, is therefore rejected.

The second and final explanation is tested in the lower half of the model in Figure 4. It shows that the lower educated suffer more from economic and cultural insecurity. Although neither type of insecurity leads people 
Figure 4. An Explanation for High Levels of Value Coherence among the Higher Educated

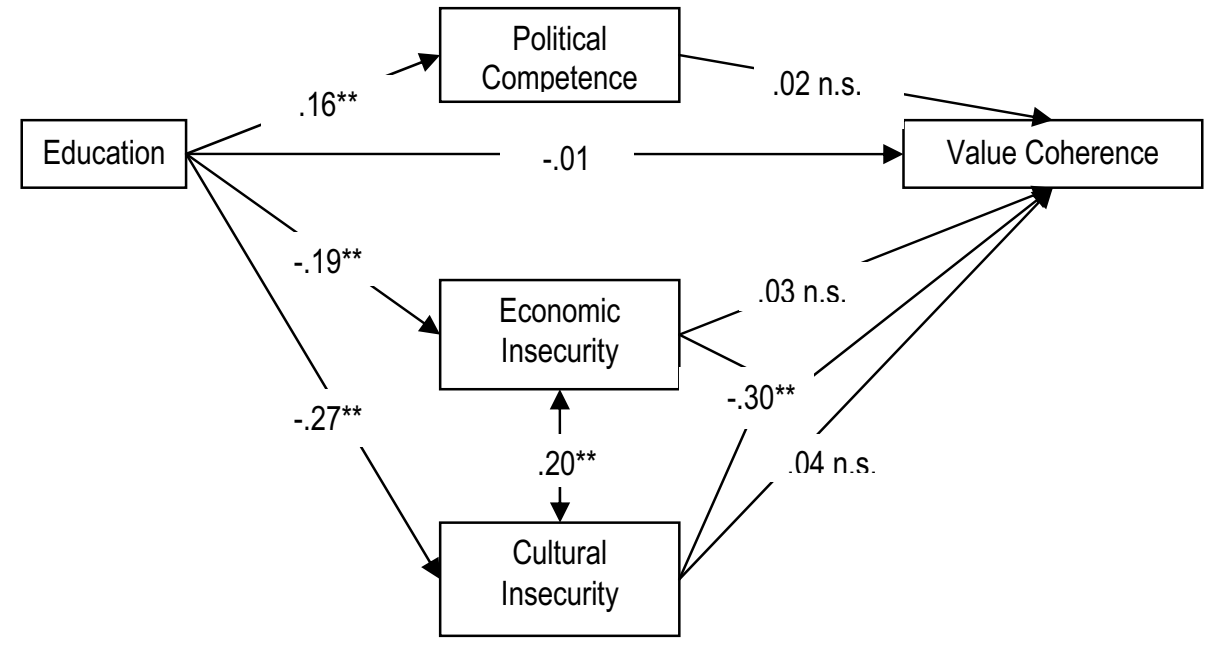

$\begin{array}{lrlrl}\text { Chi }^{2} & 54.44 & \mathrm{R}^{2} \text { value coherence } & .09 & { }^{*} \mathrm{p}<.05 \\ \text { IFI } & .93 & \mathrm{R}^{2} \text { political competence } & .03 & { }^{* *} \mathrm{p}<.01 \\ \text { CAIC } & 198.61 & \mathrm{R}^{2} \text { cultural insecurity } & .07 & n . \mathrm{n} \text {. not significant } \\ \text { RMSEA } & .08 & \mathrm{R}^{2} \text { economic insecurity } & .04 & \mathrm{~N}=1,836 \\ \text { DF } & 4 & & & \end{array}$

to value coherence, as the paths from economic and cultural insecurity are not statistically significant, these two types of insecurity do have consequences for value coherence. The strong and negative effect of the interaction term of economic and cultural insecurity shows that the specific combination of cultural and economic insecurity leads to value incoherence. The third hypothesis, that the value incoherence of the lower educated can be attributed to their economically and culturally insecure position, can therefore be accepted. Their counterparts, the higher educated, display higher levels of value coherence because they are much less likely to experience a combination of economic and cultural insecurity.

\section{Conclusion}

John Fleishman (1988:159) concluded that "social and political attitudes are organized along (...) two uncorrelated dimensions: economic welfare policy, on the one hand, and individual liberty on the other." Daniel Olson and Jackson Carroll (1992) demonstrated a few years later that substantial value coherence exists among religious elites. Both findings are correct 
because we have seen that egalitarian/ laissez-faire and authoritarian/ libertarian values are differently related in different educational categories. Those with low levels of education tend to combine progressive economic values with authoritarian cultural ones, producing value incoherence, while those with high levels of education tend to integrate both types of values into a general one-dimensional progressive/ conservative dimension, leading to value coherence.

We have tried to explain these differences in value coherence between educational categories. Firstly, a popular explanation which focuses on political competence was tested and found wanting: differences pertaining to political competence do not affect value (in)coherence. Secondly, we tested whether it is experienced insecurity that leads the lower educated to combine authoritarian and egalitarian values. We found this explanation to be tenable. Those with a low level of education simultaneously experience cultural and economic insecurity: they lack a sense of cultural wellbeing and fear that they cannot cope economically, which causes them to combine authoritarian and egalitarian values. Ideological coherence is more typical of the well educated, because of their combination of economic and cultural security. Although we have no good reasons to assume that these patterns are typical for the Netherlands, our findings obviously need replication in other Western countries. This is all the more important, because they may have important implications for two discussions within political sociology.

The first pertains to the once-popular Marxist tenet that people in lower social strata form an ideologically progressive or liberating force in history (cf. Lipset 1959, who also questions this assumption). We have found that the lower classes support economic redistribution and a comprehensive welfare state because of their economic self-interest (see also Van Oorschot 2000; Van Oorschot 2006). When those in higher social classes support these same policies, their more secure economic position makes it however quite unlikely that this support is based on economic self-interest. What is instead likely to be decisive is its rootedness in a more general and not class-based progressive political profile (e.g., Inglehart 1977).

The fact that the higher educated constitute an ideologically progressive or liberating force has major consequences for the conceptualization of the linkage between class and politics. Studies of class and voting, for example, have typically tended to conceive of a leftist-voting working class as a "natural" phenomenon (e.g., Alford 1967; Heath, Evans and Payne 1995). This assumption neglects that lower educated members of the working class may have good reasons to vote for rightist parties, while well-educated members of the middle class may have good reasons to vote for leftist ones. This is because education does not only tap into economic position, but into cultural capital as well, which causes the poorly educated 
to want to vote for leftist parties because of their economic interests and for rightist ones because of the authoritarianism that accompanies their limited cultural capital, as we have demonstrated elsewhere (Achterberg and Houtman 2006; Houtman 2003). Because of their coherent progressive ideological profile, this cross-pressure mechanism is however less likely for the well educated. In their case, economic and cultural values alike are likely to lead them to vote for leftist parties. Future research should shed light on whether such is indeed the case.

A second idea that is frequently put forward is that economic and cultural issues are increasingly growing apart, now that a "new political culture" is becoming more widespread (Clark 2001; Clark and Inglehart 1998). This assumption needs to be seriously questioned. First, at the level of political party manifestos no such increased independence has occurred in Western countries since World War II (Achterberg 2006). Secondly, our analysis leads us to expect the opposite: increasing rather than decreasing levels of ideological coherence. This is the outcome to be expected if either cultural or economic insecurity declines or if they decline simultaneously. While it is uncertain whether cultural insecurity is increasing due to processes of "detraditionalization" (Heelas 1995) and "postmodernization" (Crook, Pakulski and Waters 1992; Pakulski and Waters 1996), or decreasing due to rising levels of education, economic insecurity seems in decline in Western countries. This means that it is likely that the combination of economic and cultural insecurity becomes rarer. Indeed, some studies have reported higher levels of value coherence for the more prosperous countries (Maclntosh 1998) and increasing levels of value coherence across time (Carmines and Stimson 1982; Sullivan, Piereson and Marcus 1978). Changes in value coherence thus constitute another promising avenue for future research.

\section{Notes}

1. Not weighting the sample does not yield any different results from those presented in this article, though.

2. Although we prefer to measure value coherence in which standardized scales for libertarianism and egalitarianism are multiplied, alternative measures for coherence are, of course, possible. An alternative way to measure incoherence is to calculate the difference between the scores on both scales for each individual respondent. Another way is to calculate the variance (or standard deviation) of the scores for egalitarianism and libertarianism for each respondent separately. In both these measures higher scores stand for more value incoherence. Not surprisingly, though, these alternatives correspond very strongly with the measure for coherence used in this article (Pearson's $r$ yields -.80 or even stronger) and do not yield any substantial different results as the ones presented here. 
3. The effects of education on egalitarianism and authoritarianism differ significantly from each other $(p<.05)$.

4. The original scale for anomia included an item about the usefulness of writing public officials. This item has been replaced by the first item listed here because the original item seems to also tap into political cynicism and not so much into feelings of cultural insecurity and general mistrust.

5. Based on the values of the modification indices, we chose to let some of the error terms of the items for authoritarianism and some of the items for egalitarianism correlate with each other (as shown in figures 1 and 2) in order to increase the fit of the models. We chose not to allow correlations between the authoritarianism and egalitarianism items, because we intend to test whether both sets of items are independent of each other. Even though it obviously improves the fit of the model, allowing correlations between error terms like these should not be done in any case, (see, however, De Koster and Van der Waal (2007) who chose to do things differently).

6. A measure based on chi-square that accounts for the large number of degrees of freedom (Bozdogan 1987).

7. Incremental Fit Index, which shows the degree to which the model fits the data as compared to the complete independence model (Bollen 1986).

8. Root Mean Square Error of Approximation, showing the discrepancy between the model and the data per degree of freedom (Steiger 1990).

9. Using the modification indices, we chose first to allow a recalculation of the relationship between authoritarianism and egalitarianism for this educational group. In the subsequent steps, again, we used the modification indices to see for which groups the correlation should be recalculated.

10. Education is recoded into years of education needed to attain the highest level of education for the respondent.

\section{References}

Achterberg, Peter. 2006. Considering Cultural Conflict; Class Politics and Cultural Politics in Western Societies. Shaker Publishers.

Achterberg, Peter, and Dick Houtman. 2006. "Why Do So Many People Vote 'Unnaturally'? A Cultural Explanation for Voting Behavior." European Journal of Political Research 45(1):75-92.

Adorno, T.W., Else Frenkel-Brunswik, Daniel J. Levinson and R. Nevitt Sandford. 1950. The Authoritarian Personality. Harper and Brothers.

Alford, Robert R. 1967. "Class Voting in the Anglo-American Political Systems." Pp. 67-93. Party Systems and Voter Alignments: Cross-National Perspectives. Seymour M. Lipset and Stein Rokkan, editors. Free Press. 
Bartle, John. 2000. "Political Awareness, Opinion Constraint and the Stability of Ideological Positions." Political Studies 48(3):467-84.

Blank, Thomas. 2003. "Determinants of National Identity in East and West Germany: An Empirical Comparison of Theories on the Significance of Authoritarianism, Anomie, and General Self-Esteem." Political Psychology 24(2):259-88.

Bollen, Kenneth A. 1986. "Sample Size and Bentler \& Bonett's Nonnormed Fit Index." Psychometrika 51(3):375-77.

Bourdieu, Pierre. 1984. Distinction: A Social Critique of the Judgement of Taste. Routledge.

. 1986. "The Forms of Capital." Pp. 241-58. Handbook of Theory and Research for the Sociology of Education. John G. Richardson, editor. Greenwood Press.

Bozdogan, Hamparsum 1987. "Model Selection and Akaike's Information Criteria (AIC)." Psychometrika 52(3):345-70.

Campbell, Angus, Phillip Converse, E., Warren E. Miller and Donald E. Stokes. 1960. The American Voter. John Wiley \& Sons.

Carmines, Edward G., and James A. Stimson. 1982. "Racial Issues and the Structure of Mass Belief Systems." The Journal of Politics 44(1):2-20.

Clark, Terry N. 2001. "The Debate over "Are Social Classes Dying?" Pp. 273-320. The Breakdown of Class Politics: A Debate on Post-Industrial Stratification. Terry N. Clark and Seymour M. Lipset, editors. Westview Press.

Clark, Terry N., and Ronald Inglehart. 1998. "The New Political Culture: Changing Dynamics of Support for the Welfare State and other Policies in Postindustrial Politics." Pp. 9-72. The New Political Culture. T.N. Clark and V. HoffmanMartinot, editors. Westview Press.

Converse, Phillip, E. 1964. "The Nature of Belief Systems in Mass Publics." Pp. 206-61. Ideology and Discontent, International Yearbook of Political Behavior Research, Volume 5. David E. Apter, editor. Free Press.

Crook, Stephen, Jan Pakulski and Malcolm Waters. 1992. Postmodernization: Change in Advanced Society. Sage.

De Koster, Willem, and Jeroen Van der Waal. 2007. "Cultural Value Orientations and Christian Religiosity: On Moral Traditionalism, Authoritarianism, and their Implications for Voting Behavior." International Political Science Review 28(4):451-67.

De Witte, Hans. 1997. "De ideologische cultuur van arbeiders in Vlaanderen. Een replicatie en uitbreiding op basis van de IPSO-data." Tijdschrift voor Sociologie 18(1/2):53-78. 
Dekker, Paul, and Peter Ester. 1987. “Working-Class Authoritarianism: A ReExamination of the Lipset Thesis." European Journal of Political Research 15(4):395-415.

Eisenga, Rob, and Peer Scheepers. 1989. Etnocentrisme in Nederland: Theoretische en empirische verkenningen. ITS.

Evans, Geoffrey, Anthony F. Heath and Mansur Lalljee. 1996. "Measuring LeftRight and Libertarian-Authoritarian Values in the British Electorate." British Journal of Sociology 47(1):93-112.

Feldman, Stanley. 2003. "Values, Ideology, and the Structure of Political Attitudes." Pp. 477-510. Oxford Handbook of Political Psychology. David O. Sears, editor. Oxford University Press.

Felling, Albert, and Jan Peters. 1986. "Conservatism: A Multidimensional Concept." Netherlands Journal of Sociology 22(1):36-60.

Fiske, Susan T., and Donald R. Kinder. 1981. "Involvement, Expertise, and Schema Use: Evidence from Political Cognition." Pp. 171-90. Personality, Social Cognition, and Social Interaction. Nancy Cantor and John F. Kihlstrom, editors. Erlbaum.

Fleishman, John A. 1988. "Attitude Organization in the General Public: Evidence for a Bidimensional Structure." Social Forces 67(1):159-84.

Gibbins, Roger, and Neil Nevitte. 1985. "Canadian Political Ideology: A Comparative Analysis." Canadian Journal of Political Science 18(3):577-98.

Grabb, Edward G. 1979. “Working-Class Authoritarianism and Tolerance of Outgroups: A Reassessment." Public Opinion Quarterly 43(1):36-47.

1980. "Marxist Categories and Theories of Class: The Case of Working Class Authoritarianism." Pacific Sociological Review 23(4):359-76.

Heath, Anthony, Geoffrey Evans and Clive Payne. 1995. "Modelling the ClassParty Relationship in Britain, 1964-92." Journal of the Royal Statistical Society. Series A 158(3):563-74.

Heath, Anthony F., Geoffrey Evans and Jean Martin. 1994. "The Measurement of Core Beliefs and Values: The Development of Balanced Socialist/Laissez Faire and Libertarian/Authoritarian Scales." British Journal of Political Science 24(1):115-32.

Heelas, Paul. 1995. "Introduction: Detraditionalization and Its Rivals." Pp. 1-20. Detraditionalization: Critical Reflections on Authority and Identity. Paul Heelas, Scott Lash and Paul Morris, editors. Blackwell.

Herzon, Frederick D. 1980. "Ideology, Constraint, and Public Opinion: The Case of Lawyers." American Journal of Political Science 24(2):233-58. 
Houtman, Dick. 2001. "Class, Culture and Conservatism, Reassessing Education as a Variable in Political Sociology." Pp. 161-95. The Breakdown of Class Politics, A Debate on Post-Industrial Stratification. Terry N. Clark and Seymour M. Lipset, editors. Woodrow Wilson Center Press.

2003. Class and Politics in Contemporary Social Science, Marxism Lite and Its Blind Spot for Culture. Aldine de Gruyter.

2004. "Lipset and "Working-Class" Authoritarianism." Pp. 131-60. Civil Society and Class Politics: Essays on the Political Sociology of Seymour Martin Lipset. Irving Louis Horowitz, editor. Transaction.

Houtman, Dick, Peter Achterberg and Anton Derks. 2008. Farewell to the Leftist Working Class. Transaction.

Inglehart, Ronald. 1977. The Silent Revolution: Changing Values and Political Styles among Western Publics. Princeton University Press.

Jackson, Thomas H., and George E. Marcus. 1975. "Political Competence and Ideological Constraint." Social Science Research 4(1):93-111.

Jöreskog, Karl, and Dag Sörbom. 1999. LISREL 8: Structural Equation Modelling with the SIMPLIS Command Language. Lawrence Erlbaum Associates Inc.

Judd, Charles, and Jon Krosnick. 1989. "The Structural Bases of Consistency among Political Attitudes: Effects of Political Expertise and Attitude Importance." Pp. 99-128. Attitude Structure and Function. Anthony R. Pratkanis, Steven J. Beckler and Anthony G. Greenwald, editors. Erlbaum.

Kelly, Dennis K., and William J. Chambliss. 1966. "Status Consistency and Political Attitudes." American Sociological Review 31(3):375-82.

Kent Jennings, Mark. 1992. "Ideological Thinking Among Mass Publics and Political Elites." The Public Opinion Quarterly 56(4):419-41.

Kerr, Willard A. 1952. "Untangling the Liberalism-Conservatism Continuum." The Journal of Social Psychology 35(1):111-25.

Ladd, Everett C., and Seymour M. Lipset. 1975. The Divided Academy: Professors and Politics. Free Press.

Lamont, Michele. 1987. "Cultural Capital and the Liberal Political Attitudes of Professionals: Comment on Brint." American Journal of Sociology 92(6):1501-06.

Lerner, Robert, Althea K. Nagai and Stanley Rothman. 1991. "Elite vs. Mass Opinion: Another Look at a Classic Relationship." International Journal of Public Opinion Research 3(1):1-31.

Lipset, Seymour M. 1959. "Democracy and Working-Class Authoritarianism." American Sociological Review 24(4):482-501. 
. 1981. Political Man: Expanded and Updated Edition. John Hopkins University Press.

. 1982. "The Academic Mind at the Top: The Political Behavior and Values of Faculty Elites." Public Opinion Quarterly 46(2):143-68.

Lutterman, Kenneth G., and Russel Middleton. 1970. "Authoritarianism, Anomia, and Prejudice." Social Forces 48(4):485-92.

Maclntosh, Randall. 1998. "Global Attitude Measurement: An Assessment of the World Values Survey Postmaterialism Scale." American Sociological Review 63(3):452-64.

Marshall, Gordon, Howard Newby, David Rose and Carolyn Vogler. 1988. Social Class in Modern Britain. Hutchinson.

McDill, Edward L. 1961. "Anomie, Authoritarianism, Prejudice, and SocioEconomic Status: An Attempt at Clarification." Social Forces 39(3):239-45.

Middendorp, Cees P. 1991. Ideology in Dutch Politics; The Democratic System Reconsidered 1970-1985. Van Gorcum.

Mitchell, Robert Edward. 1966. "Class-Linked Conflict between Two Dimensions of Liberalism-Conservatism." Social Problems 13(4):418-27.

Moskowitz, Adam N., and J. Craig Jenkins. 2004. "Structuring Political Opinions: Attitude Consistency and Democratic Competence among the U.S. Mass Public." The Sociological Quarterly 45(3):395-419.

Nieumbeerta, Paul. 1995. The Democratic Class Struggle in Twenty Countries 1945-1990. Thesis Publishers.

O'Kane, James. 1970. "Economic and Noneconomic Liberalism, Upward Mobility Potential, and Catholic Working Class Youth." Social Forces 48(4):499-506.

Olson, Daniel V.A., and J. Carrol. 1994. "Religiously Based Politics: Religious Elites and the Public." Social Forces 70(3):765-86.

Pakulski, Jan, and Malcom Waters. 1996. The Death of Class. Sage.

Price, Victor. 1999. "Political Information." Pp. 591-639. Measuring Political Attitudes. John P. Robinson, Phillip R. Shaver and Lawrence S. Wrightsman, editors. Academic Press.

Roberts, Alan H., and Milton Rokeach. 1956. "Anomie, Authoritarianism, and Prejudice: A Replication." American Journal of Sociology 61(4):355-58.

Scheepers, Peer, Rob Eisenga and Leo Van Snippenburg. 1992. "Working-Class Authoritarianism: Evaluation of a Research Tradition and an Empirical Test." Netherlands Journal of Sociology 28(2):103-26. 
Srole, Leo. 1956. "Social Integration and Certain Corollaries: An Exploratory Study." American Sociological Review 21(6):709-16.

Steiger, James H. 1990. "Structural Model Evaluation and Modification: An Interval Estimation Approach." Multivariate Behavioral Research 25(2):173-80.

Sullivan, John L., James E. Piereson and George E. Marcus. 1978. "Ideological Constraint in the Mass Public: A Methodological Critique and Some New Findings." American Journal of Political Science 22(2):233-49.

Svallfors, Stefan. 1991. "The Politics of Welfare Policy in Sweden: Structural Determinants and Attitudinal Cleavages." British Journal of Sociology 42(4):609-34.

Van Oorschot, Wim. 2000. "De legitimiteit van sociale zekerheid; Een sociologische analyse van motieven voor solidariteit." Pp. 35-76. Sociale zekerheid: een ander gezichtspunt; Toekomstperspectief vanuit vier disciplines. Saskia Klosse, editor. die Keure.

. 2006. "Making the Difference in Social Europe: Deservingness Perceptions among Citizens of European Welfare States." Journal of European Social Policy 16(1):23-42.

Van Snippenburg, Leo, Carlo P.M. Hageman and Paul Hendriks Vettehen. 2002. "Politieke kennis en mediagebruik in Nederland." Mens en Maatschappij 77(1):65-79.

Wright, Erik Olin. 1985. Classes. Verso.

Zaller, John R. 1992. The Nature and Origins of Mass Opinion. Cambridge University Press. 